\title{
ROSALÍA, MAR DE FONS, A ESPRIU I MARÇAL
}

\section{Marta Font i Espriu}

Centre Dona i Literatura, Universitat de

\section{Barcelona}

doi:10.17075/rcsxxi.2014.057

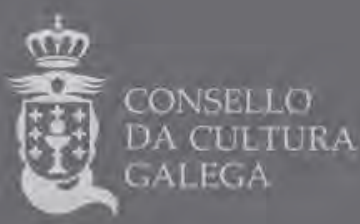



Sento cremar, gelada, l'estructura de ferro.
La miro, fosca i nua, com si fos una dona
a la que he estimat sempre.
La vida ha anat quedant-se sota el fred
dels hiverns a les obres.
«Un arquitecte pensa a l'alba en Rosalía»
Joan Margarit

\section{INTRODUCCIÓ}

Rosalía de Castro arriba a nosaltres des dels sons del seu gran mar, amb els ecos de les campanes de Bastabales, als braços molls del dolor i de l'angoixa. Arriba, a més, d'un segle que es va mostrar, a la península, feréstec, tossut i violent. Hi va haver, ben cert, la tibantor d'una modernitat conflictiva, que no va arrelar mai del tot a Espanya. I Rosalía va retornar, des de la seva sensibilitat i geni, personals i nous, la veu al poble: les cançons de Sant Joan, les romeries a les ermites, les feines dels camps i de la cura dels petits... Hi intuïm, també, el laberint del qual començaven a sortir, amb prou feines, les llengües ibèriques no hegemòniques. Quasi abolides, maldaven per refer un camí ja massa anys cobert d'ombres i d'oblit; per tornar, d'enllà dels silencis, amb els mots a les mans.

Rosalía enllesteix, en aquest buit, una coratjosa aventura. I és cap endins que ho fa, és cert, fins al fons de la seva condició de dona, de filla il.legítima i de «nació oprimida». Triplement privada, doncs, com a la «Divisa» marçaliana, d'un espai que fos propi i ja construït, reneix de si mateixa, obligada a bastir, des dels dolors i les mancances, una nova enunciació poètica. Finalment hi renunciarà, a contracor i víctima de les crítiques injustes, al gallec. Per tot plegat, podem veurehi certa desfeta personal:

Tras de inútil fatiga, que mis fuerzas agota,

caigo en la senda amiga, donde una fuente brota, 
siempre serena y pura;

y con mirada incierta, busco por la llanura

no sé qué sombra vana o qué esperanza muerta,

no sé qué flor tardía de original frescura

que no crece en la vía arenosa y desierta

(Castro 2009: 760)

Col-lectivament, en canvi, seran els poemes gallecs de Rosalía els que arribaran més lluny. Travessaran la península i trobaran mirall, també, a casa nostra, tot oferint no només l'exemple de dona, capaç de confessar «sinceritat» — sota el paraigües retòric de l'enunciació adequadament femenina, és a dir, «la dulzura infantil, la modestia y el pudor (Lafollette 1986: 66) —, i d'afirmar una veu pròpia i col-lectiva, al mig d'un segle d'homes i contrari als pobles sotmesos; sinó també d'una poeta que refa els vells ritmes del poble i en proposa de nous, originals i trencadors, a despit de les crítiques i les incomprensions. La seva imatge bé que la podem veure reflectida a la manera com Salvador Espriu s'aferrà, sempre, al compromís amb la llengua catalana, a través de la poesia, o, en el projecte políticopoètic de Maria-Mercè Marçal, en el qual representarà l'escriptura (la seva «llengua abolida») com un mitjà de subversió de les construccions discursives, és a dir, retòriques, que han obstaculitzat la possibilitat d'expressió de la dona en l'escriptura poètica.

Amb aquestes pàgines us proposo escoltar aquest mar de fons rosalià com a horitzó de lectura a la poesia de Salvador Espriu i Maria-Mercè Marçal. Presentaré, doncs, intuïcions, suggerències i possibles actualitzacions de la veu rosaliana per obrir i il.luminar espais discursius compartits entre els tres poetes. Així mateix, al centre hi ubicaré les tensions entre la construcció d'un jo poètic personal i la projecció de la representació de la identitat col-lectiva, entesa com a espainació. Em giraré, de primer, cap a la mirada endins de Salvador Espriu, capaç de travessar la foscor del silenci de l'opressió i sortir-ne més digna, més forta, més valenta. Amb una poesia que buscà en el destí personal la justificació de la vida pròpia i la del poble. 
Rosalía és dona i en fa llenguatge, espai i presència. I escull, en part, el dolor, la nostàlgia, la mirada preferent cap al destí i la melangia com a marcs des d'on fixa la subjectivitat poètica. En aquest sentit, Cantares gallegos, en l'obra rosaliana, s'erigirà com a Altre, en majúscules, a partir del qual construirà les tensions entre el jo líric i el «nosaltres», és a dir, entre l'enunciació (la constitució del subjecte poètic) i la identitat (individual i col-lectiva) a la qual, paradoxalment, ella mateixa ha donat veu. Per això, l'obra de Rosalía esdevé un moviment pendular del «nosaltres» cap al «jo», fet que ens permet revisitar el que Alonso Montero ha categoritzat com «la palabra solitaria» — tal com ens recorda López-Casanova (1986: 133)— de Follas novas i En las orillas del Sar com un anunci de l'experiència moderna del paisatge. Michel Collot la descriu de la següent manera:

L'expérience moderne du paysage tend vers un fond insondable qui ne saurait faire l'objet d'une véritable perception. Ce qui l'attire dans l'horizon, ce n'est pas ce qu'il met en vue, c'est qu'il ouvre l'espace à perte de vue sur l'invisible. Et cette perte de vue s'accompagne pour le poète d'une perdition de soi, d'une plongée dans des profondeurs intérieures qui échappent à l'inspection de la conscience (1989: 27-28).

Així, doncs, aquest viratge cap endins, cap a «iDo íntimo!», s’observa en el poema "¡Adiós!», on trobem clarament una estructura que diferencia els dos plans. Per una banda, la primera estrofa, «Adiós! montes e prados, igrexas e campanas; / ¡adiós! Sar e Sarela cubertos d'entramada; / ¡adiós! Vidán alegre, moíńos e hondonadas» (Castro 2009: 430), amb clares ressonàncies amb el cant quinzè de Cantares gallegos — tan conegut gràcies a Amancio Prada—: "Adiós ríos, adiós fontes, / adiós regatos pequenos, / adiós vista dos meus ollos, / non sei cuando nos veremos» (id.: 204). I no tan sols això, sinó l'estrofa opera gairebé com una palinòdia, és a dir, que recull grosso modo la representació de la Galícia que ella ha tematitzat a Cantares gallegos. Per altra banda, a la segona estrofa el jo rosalià irromp el text, trenca l'evocació del paisatge (espai col-lectiu), amb l'afirmació d'un «jo» reiterat i exclamatiu «I eu... mais eu nada temo no mundo / ¡que a morte me tarda!». 
Així ens encamina cap a la desfeta d'un «jo», la pèrdua de si mateixa originada per la pèrdua del paisatge, de l'horitzó, tal com afirma Collot. De tal manera, la mort ascendeix a la categoria de desig. Així mateix, n'ha fet, de la mort, divisa inconfusible, com Espriu ens mostra en posar sota els seus auspicis la primera secció del poemari El caminant $i$ el mur, titulada «Les ombres, el riu, el somni perdut», amb el vers «Quero quedar ond'os meus dôres foron» (Espriu 2009: 161).

Amb aquest intertext, breu i insinuant, no tan sols és una aclucada d'ull a l'obra de Rosalía, que trobem ratificat a una entrevista al poeta als anys setanta, on considera el corpus rosalià com el cim de la poesia gallega — «Creo que ustedes, los gallegos, a pesar de tener grandes poetas, no han superado los mejores momentos de Rosalía» (García 1995: 13)—, sinó que activa el mar de fons de símbols compartits. En aquest sentit, no hi ha, potser, símbol més fascinant, en sentit literal, com a mirall del jo poètic, com a tu provocador des del seu silenci, que el mar en tota la seva immensitat. Seductor i fascinador, el mar representa no tan sols la totalitat captivadora de la mort, d'allò infinit, l'anul-lació del «jo», de la passió turmentada de Rosalía o la meditació solipsista del profetisme espriuà, el mar és la projecció impossible, la frontera inabordable del poble oblidat i injustament tractat:

A la vora de la mar. Tenia una casa, el meu somni, a la vora de la mar

Alta proa. Per lliures camins d'aigua, l'esvelta barca que jo manava.

Els ulls sabien tot el repòs i l'odre d'una petita pàtria. (Espriu 2009: 47)
Dígoch'este adiós chorando desd'a beiriña do mar. Non m'olvides, queridiña, si morro de soidás... tantas légoas mar adentro... ¡Miña casiña!, ¡meu lar! (Castro 2009: 208) 
Aquest desplegament del «jo» — com a receptacle de la paraula i de la llengua, com a espai íntim on es resolen simbòlicament conflictes en els quals el poeta, assumeix, implícitament o explícita, una representació del ser del poble- és una de les dimensions més interessants per entendre com, en contextos històrics diferents, conflictes de naturalesa política cíclicament reactualitzats adquireixen expressions estètiques distants, és cert, però que s'illluminen mútuament, tan en les similituds deliberades, com en les diferències inevitables. Fem atenció a un altre poema d'Espriu:

\section{RIU}

Aquell riu que sabíem enllà del gran silenci del camí ens encalma de sobte la mirada.

Escollit entre prínceps captaires, ja en la riba feliç, pel vespre passo portant llum de paraules.

He convertit vells somnis en la petita ofrena d'una veu. De l'angoixa del torrent m'allibero, oblidant i perdent-me en lentes aigües clares. (Espriu 2009: 153)

És evident que el «riu» deriva de la imatgeria clàssica de la mort. Però és deliberadament desretoritzada, desactivada la menció erudita del nom Aqueront, oferint a canvi un espai comú per referir-se a la mort: «el gran silenci». Tot el moviment conceptual del poema segueix fidelment el trajecte mental de l'imaginari grecollatí. Tot i amb això, ens aturarem a al «vespre», el crepuscle on només il.luminen les paraules; els somnis vells d'eternitat, del poble i del «jo». Aquests dos plans 
s'identifiquen mútuament al significar-se un a l'altre. Només resta l'ofrena d'una veu, aquesta llum petita de paraules, allò que el jo poètic deixa al poble abans de marxar a la vora de la mort. És a dir, només la poesia, aquest mateix poema, és el que queda a la sortida del laberint de la vida. Aquesta pervivència del «jo», mínima, però de valor colllectiu, no és ni tan sols considerada en els moments d'ambició de la mort per part de Rosalía.

El seu apassionament, la seva soledat, la falta d'identificació entre el seu «jo» intens i el nosaltres extens, que la critica i l'encotilla, provoca que només pugui plantejar-se la mort, visualitzar-la, en termes d'una anul-lació del «jo» deliberada en un mar violent i devorador.

Co seu xordo e constante mormorio atraim'o oleaxen dese mar bravío, cal atrai das serenas o cantar.

- Neste meu leito misterioso e frío, dime, ven brandamente a descansar.

El namorado está de min... o deño, i eu namorada del.

Pois saldremos co empeño, que s'el me chama sin parar, eu teño unhas ansias mortais d'apousar nel.

(Castro 2009: 422)

A Rosalía no hi trobem una reconstrucció d'una perdurabilitat atenuada, com sí que ens ofereix Espriu, per al qual la poesia l'enfronta a una experiència controlada i elaborada de la mort. Així mateix, recrea i menciona constantment els seus morts, no com a seguici tradicional a la manera gallega (la Santa Compaña), sinó com a miralls premonitoris de la dissolució del «jo», que els reviu i evoca en els mateixos poemes on es volca lentament cap al seu fi meditat.

\footnotetext{
PARCA

Jo, només, i les hores,

i els meus morts que s'allunyen
} 
a poc a poc per llargues

rengleres de silenci.

\section{[...]}

On per què? No sabria

dir-m'ho mai, però sento

com aquells dits em filen,

enllà de mars, d'escuma

d'estranys somnis, un únic

camí sense fugida.

(Espriu 2009: 146)

En canvi, per a Rosalía l'evocació dels "seus morts», és justament la pèrdua d'una identitat, l'horitzó esborrat, «Estranxeira na súa patria»:

Interminable procesión de mortos,

uns en corpo nomais, outros no esprito,

veu pouco a pouco aparecer na altura

do direito camiño

que monótono e branco relumbraba,

tal com'un lenzo nun herbal tendido.

Contemprou cal pasaban e pasaban

collendo hacia o infinito,

sin que ó fixaren nela

os ollos apagados e afundidos

deran siñal nin moestra

d'habela nalgún tempo conocido.

(Castro 2009: 480, 482)

Si seguim endavant, un altre símbol compartit que s'assenta sobre el moviment pendular del «jo» al «nosaltres», és la imatge de l'arbre. 
L'arbre, com a símbol de vida que comunica els espais de la terra i del cel, representa una imatge de força, de la vida i moltes vegades, de la solidesa de la pàtria. La seva verticalitat fa visible la comunicació natural i desitjable entre el passat que les arrels absorbeixen i el futur que s'eixampla a les branques. La seva quietud condensa i fa visible amb paradoxal estatisme el fluir del temps. No ens caldrà, ara, insistir massa, amb els imaginaris vinculats al Pi de les tres branques o a l'arbre de Guernica. A Rosalía trobem, concretament, el roure, com a espai de vida i símbol de la nació: pel seu retorn es prega amb una mena d'invocació de renaixença. Significativament, és a En las orillas del Sar on aquest símbol es desenvolupa a través d'un poema cabdal (Acereda 2008) i, també, de manera recorrent, en altres poemes que refereixen a d'altres arbres i boscos. El Roure («árbol patrio») és arbre acollidor; a les seves branques i ombra tornarà la vida en tota la seva complexitat i varietat. Aquest símbol ocupa el complex poema XIV i mereix el títol de «Los Robles», refugi de les fades que han de tornar també per teixir les garlandes de l'heroi gallec.

¡Torna presto a poblar nuestros bosques,

y que tornen contigo las hadas

que algún tiempo a tu sombra tejieron

del héroe gallego

las frescas guirnaldas!

(Castro 2009: 787-788)

No és que Rosalia abraci una poètica de pretensions èpiques, guerreres; més aviat, com veiem, evoca uns éssers mítics i femenins, un espai de renaixença simbòlic i viu, de celebració de la naturalesa recuperada com a sòl de la pàtria somiada.

Explícitament, no veiem la projecció del «jo» en el símbol de l’arbre, que queda com a representació de la pàtria que ha de tornar. Aquesta projecció, en canvi, sí que té lloc a voltes, als poemes d'Espriu. Els arbres, moltes vegades els xiprers de Sinera, omplen com a fons l'espai del poema. A vegades, però, n'ocupen el centre, fins al punt de fondre's, totalment, amb l'esperit d'Espriu. Les arrels es comuniquen amb la terra, espais dels morts i del passat, mentre que les fulles airegen la veu, quasi profetica, deshumanitzada i fosa al símbol del nosaltres, de la pàtria. 
Això és ja parlar des de dins del símbol, que ja no és només objecte, sinó que esdevé mirall, i més encara, imatge feta cos propi i punt de partida del missatge i de l'experiència de la subjectivitat com a eix ja col-lectiu i perdurable. Fixem-nos en les tres primeres estrofes del poema XII del Final del laberint.

Esguarda l'arbre sol:
arrelat en fondàries
d'un somni dolorós
mira com vaig arbrant-me.

En suplicar més llum

d'estrelles allunyades

els braços molt alçats

esdevenien branques.

A beure de la font

de les meves paraules

per l'ordre dels cimalls

davallen ocells d'alba.

(Espriu 2009: 226)

I tanmateix, Espriu necessita sentir la transcendència d'aquest símbol de vida. Imaginar el després, trobar en la mort un espai de reconciliació i plenitud mística, d'unitat absoluta de tot allò que existeix. Tot just tres poemes més endavant, llegim això:

És acabada la mort de l'arbre, amb la destral ja tallaves el tronc. És acabat el vell dolor de l'arbre i te l'enduies a fer-ne gran foc.

Caves la terra esdevinguda eixuta on s'assecaven les arrels del plor.

Caves endins de les teves paraules: 
no saps trobar-ne la cançó.

(Espriu 2009: 229)

Aquesta esterilitat, aquesta privació absoluta de vida, que deixa esmorteïdes les paraules, conflueix, molt curiosament, amb la imatge de cavar endins de les paraules, buscar-ne el fons, el significat de vida i cançó, com també Rosalía maldava per cavar endins dels seus pensaments, trobar-ne la fondària, l'arrel última del dolor. Resulta emocionant veure com ambdós llenguatges, personalíssims, es retroben tot fonent imatges, invitacions secretes per emmirallar Espriu i Rosalía:

Cava lixeiro, cava,

xigante pensamento,

cava un fondo burato ond' a memoria

do pasado enterremos:

¡á terra cos difuntos!

¡Cava, cava lixeiro!

(Castro 2009: 462)

II

Arribats aquí, és el moment de Maria-Mercè Marçal, hereva de les dones, hereva de Rosalía, tal com evidencia el següent poema de Sal oberta:

T'he portat de Galícia, confós a la senalla,

Una mica de terra i una mica de mar.

El sègol que ha aplegat l'orri de la tendresa,

I un borrissol de boira del cimal d'un carballo.

L'or del Miño collit a les planes trencades

De la geografia. La saudade vermella:

O lar de Brehogan avui bull, i les mans

Ben closes fan un puny, ben obertes, l'estrella. 
T'he portat un clau d'or, de ferro o bé d'amor

Que m'he sentit granar a l'hort de Rosalia.

Un mastegall de verd i un deliri de blau

Emigrant, terra endins, per la mar sense tanques.

I el cop d'ull d'una meiga que m'ha fitat al vol:

A mal donat d'enyor no li cerqueu metgia.

(Marçal 2000: 195)

L'atribut central de la llengua poètica de Marçal és el subvertir el camp simbòlic per revisar i actualitzar una llengua literària catalana que permeti l'expressió d'una subjectivitat lírica en femení, en tant que subjecte agent de la creació i de la seva representació. Meri Torras, a l'article «Escriure el desig al cos del text. Escriptures i lectures lèsbiques a la literatura catalana», subratlla la figura de la poeta pel que fa al treball constant, tant en l'obra de creació com en la tasca intel-lectual, "per trobar aquest espai de representació per a aquesta sexualitat foragitada de la textualitat hegemònica» (2007: 139). Aquest projecte es construeix des del que Marçal anomena Llengua abolida i que dóna títol a tota la seva producció poètica. Per tant, la poesia marçaliana aposta per un exercici lingüístic i retòric per crear noves representacions textuals del gènere femení, fet indissociable de la recerca de noves formes d'enunciació del jo líric. I és aquí on l'empremta de Rosalía té un paper més que significatiu. És cert, que en el projecte marçalià, tal com subratllava Fina Llorca al 2004, l'establiment de la filiació femenina és un dels objectius de la seva obra: «Passant a Sal oberta, encara que res no ho indiqui en la primera edició, la cançó 'Si el mar tingués baranes' parteix d'un vers de Rosalia de Castro, poeta fundacional per a la llengua gallega, cosa que havia estat interpretada per Marçal, en ocasió d'una trobada a Vigo de poetes peninsulars i de les Illes, com una gran sort per a la poesia d'autoria femenina que havia de venir» (Llorca 2004: 221).

Sigui com sigui, Rosalía no tan sols esdevé nom i endreça sinó que Marçal en destil.la, tal com hem vist en el poema, la simbologia i l'incorpora en el que Calvo anomena la creació d'un «diccionari nou» (2008: 101), dins del qual té un paper molt important el fet de recollir les veus de dona en la producció cultural popular: els cants populars, les cançons de bressol, etc. I si a més afegim, com ens recorda 
Helena González, «que és una meniña gaiteira y no un guerrero o un hombre luchador quien soporta la voz principal de Cantares» (2012: 196), la imatge de «l'hort de Rosalía» encara pren més sentit. Un exemple de caire anecdòtic però no per això anodí és la tècnica onomatopeica, la qual se sustenta en la musicalitat del vers:

redobre das castañetas, xás-co-rras-chás das cunchiñas, xurre-xurre das pandeiras, tambor do tamborileiro, gaitiña, gaita gallega (Castro 2009: 218)
Si pogués ser gitana i endur-te'm al país on les móres maduren al caliu de la lluna — dins del sac ca-ta-crac, per l'ai dolç de / l'abís-

(Marçal 2000: 247)

Dins de la imatgeria popular, també, podríem parlar de la recuperació de les identitats femenines com les fades i les bruixes. Però el que sí m’interessa citar, és com en el relat de l'absorció de l'altre en el context amorós, Marçal recupera la imatge de la vampira, a través del verb xuclar «cal si unha meiga chuchona a miña sangre bebera» (Castro 2009: 218):

Però no. Deixảm només que et xucli el carmí viu de la ferida, que et llepi el teu neguit fins a amoixar-lo, fins que la sang torni a les venes, amansida i sense venjança.

(Marçal 2000: 365)

Deien que es deia Amor.

Dia a dia sentia

El seu mossec brutal

—vampíricament bell.

(ibid.) 
Aquests exemples, tan sols ens serveixen per assentar de forma preliminar coincidències entre ambdós escriptures poètiques. Ara bé, per tal de seguir el mateix recorregut que en el cas d'Espriu, prendrem la concatenació simbòlica entre: desig-mar-mort.

Gràcies a Marçal podem parlar d'una agitació radical de l'entramat poètic català, desestabilitzadora dels tòtems homogeneïtzadors en la representació de la dona en la poesia i marcada per la recerca d'una sensualitat textual (cos i llenguatge). Amb això, la poeta convocarà paraula, cos i ritme en el procés d'escriptura per cercar un espai diferenciat d'expressió. Grosso modo els tres aspectes claus del projecte literari marçalià es podrien sintetitzar amb els punts assenyalats per Josep-Anton Fernàndez: «la redefinició de la subjectivitat femenina, l’assumpció de la maternitat i l'expressió de l'amor lèsbic, fins aleshores inaudit en la literatura catalana» (2004: 203). Atès això, un dels temes centrals que travessen tota l'obra és la representació del desig i l'alteritat amorosa. I, justament, en aquest marc el mar emergeix com l'espai altre, frontera infranquejable. És la projecció de la pèrdua dels límits del subjecte en el context amatori.

El Tot que es fon, és només el meu Buit?

I, inabastable en l'alta solitud,

la teva mar, sols el meu suïcidi?

(Marçal, 2000: 373)

En aquest sentit, Marçal absorbeix l'imaginari de Rosalía en la seva cosmologia personal. Fins a tal punt, que, per una banda, podem trobar intertextos claríssims i evidents, on l'evocació de Rosalía significa el propi poema:

Si o mar tivera barandas

Fórate ver ao Brasil,

Mais o mar non ten varandas

Amor meu, ¿por dond'hei d'ir?

(Castro 2009: 234)
Si el mar tingués baranes i el tomb del cel mollons prou sabria on cercar-te, mes no hi vindria, no.

(Marçal 2000: 219) 
$\mathrm{O}$, per altra banda, trobem l'elaboració del símbol rosalià incorporat dins del seu propi llenguatge poètic: «L'escala fosca / del desig / no té barana» (Marçal 2000: 87).

Fem el salt, ara, cap al símbol de l'arbre. A l'obra de la poeta catalana aquest darrer és especialment remarcable, tenint en compte que és una imatge en constant resignificació, sobretot, des de la sinècdoque, a partir de les «arrels», «branques» o «escorça». Però encara més sorprenent és el verb «arbrar-se», que aporta la idea d'obertura de la terra, Marçal apel-la, doncs, el trencament dels límits del cos, la ruptura de la contenció, per créixer a totes direccions i expandir-se com el «cactus» de Maria-Antònia Salvà. Anteriorment, he comentat que Rosalía no projecte el jo líric a la imatge de l'arbre, sinó que n'és representació del col-lectiu. Ara bé, gràcies al «cactus» de Salvà i la lectura simbòlica que n’ha fet Marçal: «No puc llegir, doncs, els deu versos que formen la composició esmentada sense que el seu sentit simbòlic se'm manifesti amb força $i$, potser anant molt més enllà de les intencions conscients de la poeta mallorquina, se'm converteixin en una mena d'al.legoria de la dona escriptora, aquella que Tillie Olsen, en un llibre memorable, va batejar de "supervivent"» (Marçal 2004: 87); es pot establir un paral.lel entre el «roure», símbol del col.lectiu, amb els versos «Non follas novas; ramallo / de toxos e silvas sós» (Castro 2009: 408), símbol de la seva pròpia escriptura. Aquestes fulles com esbarzers, sense olor ni frescor representen la consciència d'una escriptura seca i dolorosa, que de la mateixa manera que M. Antònia Salvà erigeixen una al-legoria de la lluita personal davant de ser dona i escriptora: «Perquè, de fet, ens trobem davant la primera dona poeta important de la història de la poesia catalana. Abans d'ella, i en català, a penes havien trobat expressió poètica l'experiència femenina del món i de les coses, el peculiar punt de visa que confereix, si més no, una inserció diferent en la realitat i la història, la vivència transformada en ritme i en sentit per una paraula de dona» (Marçal 2004: 88). I aquesta representació també és Rosalía de Castro. 


\section{REFERÈNCIES BIBLIOGRÀFIQUES}

ACEReda, Alberto (2008): «Rosalía de Castro y la visión poética de Galicia», Revista de Literaturas Modernas, 37-38 (http://bdigital.uncu.edu.ar/4910).

Calvo, Lluïs (2008): «Maria-Mercè Marçal o la fusió dels pols: cos, alteritat, desig», Reduccions, 89, 90-119.

Castro, Rosalía de (2009): Poesía completa. [Juan Barja (ed. bilingüe)]. Madrid, Abada Editores.

Collot, Michel (1989): La poésie moderne et la structure d'horizon, París, Presses Universitaires de France.

Espriu, Salvador (2009): Cicle líric, Barcelona, Edicions 62.

FERnÀNDEZ, Josep-Anton (2004): «Subversió, transició, tradició: política i subjectivitat a la primera poesia de Maria-Mercè Marçal», Lectora. Revista de Dones i Textualitat, 10, 201-216.

García, Xosé Lois (1995): «Falando con Salvador Espriu», El Progreso, Lugo, 13-10-1974. Reimprès: Francesc Reina (ed.), Salvador Espriu. Enquestes i entrevistes, II (1974-1985), Barcelona, Edicions 62 (Obres Completes-Edició crítica), 9-14.

GonzÁlez, Helena (2012): «La musa, la estatua y la vampira», en Helena González Fernández / María do Cebreiro Rábade Villar (eds.), Canon y subversión. La obra narrativa de Rosalía de Castro, Barcelona, Icaria, 179-199.

Lafollette, Martha (1986): «Rosalía de Castro: su autoconcepto como poeta y como mujer», en Actas do Congreso internacional de estudios sobre Rosalía de Castro e o seu tempo, Santiago de Compostela, Consello da Cultura Galega / Universidade de Santiago de Compostela, I, 65-72.

López-Casanova, Arcadio (1986): «Estilística do símbolo na poesía rosaliana», en Actas do Congreso internacional de estudios sobre Rosalía de Castro e o seu tempo, Santiago de Compostela, Consello da Cultura Galega / Universidade de Santiago de Compostela, I, 133-141.

LLORCA, Fina (2004): “"Terra on arrelar”: la construcció de genealogia literària femenina segons Maria-Mercè Marçal», Lectora. Revista de Dones i Textualitat, 10, 217-231.

MarçAL, Maria-Mercè (2000): Llengua abolida (1973-1988), València / Barcelona, Poesia 3i4.

MarÇAL, Maria-Mercè (2004): Sota el signe del drac. Proses 1985-1997. [Mercè Ibarz (ed.)]. Barcelona, Proa.

Torras, Meri (2007): «Escriure el desig al cos del text: escriptures i lectures lèsbiques a la literatura catalana contemporània», en Julian Acebrón / Rafael M. Mérida (eds.), Diàlegs gais, lesbians, queer / Diálogos gais, lesbianos, queer, Lleida, Universitat de Lleida, 133-150. 
